\title{
O significado espiritual da casa terrena
}

The spiritual meaning of the earthly home

El significado espiritual de la casa terrenal

Ana Klaudia de Almeida Viana Perdigão Programa de Pós-graduação em Arquitetura e Urbanismo, UFPA, Brasil klaudiaufpa@gmail.com

\section{Luci Gimenes}

Faculdade de Educação, USP, Brasil

lugime@usp.br 


\title{
Revista Científica ANAP Brasil
}

\author{
ISSN 1984-3240 - Volume 14, número 32, 2021
}

\section{RESUMO}

Abordam-se neste artigo elementos introdutórios para uma abordagem sobre a casa física como elo do desenvolvimento humano e como suporte de experiência na matéria com vistas à evolução espiritual. Utilizam-se textos do Espiritismo kardecista para buscar aproximações entre os vários mundos que servem de morada da vida humana como um condicionamento na experiência física. Mas vai além: chegando até as ciências do espaço que dão suporte à experiência humana para a produção do ambiente de morar no planeta Terra, mostrando as conexões existentes entre os mundos habitados pelos seres em evolução pelo infinito e pela imensidão da obra de Deus. A compreensão do ambiente físico na experiência humana se mostra objetivamente, permitindo a discussão sobre a casa terrena e seu significado espiritual, abordando-se a interdependência de mundos habitados.

PALAVRAS-CHAVE: Mundos habitados. Casa terrena. Regeneração. Planeta Terra.

\section{ABSTRACT}

This article addresses introductory elements for an approach to the physical house as a link to human development and as a support for experience in matter with a view to spiritual evolution. Texts from Kardecist Spiritism are used to seek approximations between the various worlds that serve as the dwelling place of human life as a conditioning in the physical experience. But it goes beyond: reaching the space sciences that support the human experience to produce the environment of living on planet Earth, showing the existing connections between the worlds inhabited by evolving beings, by the infinite and the immensity of God's work. The physical environment understanding in human experience is objectively shown, allowing the discussion about the earthly house and its spiritual meaning, approaching the interdependence of inhabited worlds.

KEYWORDS: Inhabited worlds. Earthly home. Regeneration. Planet Earth.

\section{RESUMEN}

Este artículo aborda elementos introductorios para una explanación sobre la casa física como vínculo con el desarrollo humano y como soporte de la experiencia en la materia con miras a la evolución espiritual. Los textos del Espiritismo Kardecista se utilizan para buscar aproximaciones entre los distintos mundos que sirven como morada de la vida humana como condicionante en la experiencia física. Pero va más allá: llegando a las ciencias espaciales que sustentan la experiencia humana para la producción del entorno de vida en el planeta Tierra, mostrando las conexiones existentes entre los mundos habitados por seres que evolucionan, por la infinitud y por la inmensidad de la obra de Dios. La comprensión del entorno físico en la experiencia humana se muestra objetivamente, permitiendo la discusión sobre la casa terrena y su significado espiritual, acercándose a la interdependencia de los mundos habitados.

PALABRASCLAVE: Mundos habitados. Hogar terrenal. Regeneración. Planeta Tierra. 


\title{
Revista Científica ANAP Brasil
}

\author{
ISSN 1984-3240 - Volume 14, número 32, 2021
}

\section{INTRODUÇÃO}

A relação que o ser humano estabelece com a dimensão física, especialmente com a casa física, tem permitido grandes reflexões e mudanças deflagradas com os acontecimentos em curso desde o final de 2019 pela transmissão da Covid-19 por meio do novo coronavírus, levando à instalação de uma crise sanitária no planeta Terra em 2020, quando foi decretada uma pandemia pela Organização Mundial de Saúde (OMS).

Trata-se de um momento único, já que o início do século XXI conjuga uma série de acontecimentos planetários, confirmando o fato de que existe um processo intenso em curso, evidenciado por uma crise no ambiente físico e humano, que aguarda por mudanças estruturais.

O planeta Terra está atravessando um momento paradigmático, pois está saindo das provas e expiações (Kardec, 2013) e entrando em um patamar de um mundo de regeneração. Tal fato repercute na intensificação dos processos evolutivos do ser humano com implicações de natureza física e espiritual.

O plano físico da existência humana na Terra permite um conjunto específico de aprendizados necessários para a evolução espiritual, o que ganha um alcance bem mais amplo nas palavras de Jesus Cristo, quando afirma que "há muitas moradas na casa de meu Pai" (Kardec, 2013, p. 57), nesse sentido, circunscreve-se um universo ampliado sobre o importante papel da casa terrena e de seu significado espiritual.

São muitos níveis de morada entre o físico e não físico e, conforme os ensinamentos dos espíritos, são muitas as variações dos mundos entre as diversas dimensões. As condições deles quanto ao grau de adiantamento ou de inferioridade dos seus habitantes em relação a Terra são diversas: uns ainda inferiores física e moralmente; outros na mesma categoria que o nosso e outros que lhe são mais ou menos superiores a todos (Kardec, 2013).

Por sua vez, a dimensão física dos mundos varia conforme a evolução espiritual dos seres. Desse modo, torna-se de fundamental importância compreender o cenário no qual as experiências se desenvolvem para que o plano reencarnatório possa se concretizar.

Assim sendo, pretende-se introduzir aqui elementos para uma discussão sobre a casa física como elo ao desenvolvimento humano e como suporte de experiência na matéria em caminho espiritual. De um modo geral, ela mostra-se como espaço para amadurecimento emocional, mental e espiritual pela experiência humana na dimensão física.

\section{O MUNDO FÍSICOE A EXISTÊNCIA DA VIDA EM OUTROS MUNDOS}

Foram muitos séculos até a compreensão de que "Deus povoou de seres vivos os mundos, concorrendo todos esses seres para o objetivo final da Providência" (Kardec, 2013, p. 71). Sem os recursos tecnológicos que o progresso científico nos oferece hoje, torna-se difícil defender uma resposta sobre a existência ou não de vida além do planeta Terra, pelo menos, até onde nossa vista alcança, ainda que tenhamos equipamentos avançados.

Contudo, acreditar que só haja no planeta que habitamos a existência de vida, de certa maneira, significa duvidar da sabedoria de Deus, que não fez coisa alguma inútil. Aos mundos criados por Ele existe uma destinação mais séria do que possa imaginar: "Aliás, nada há, nem na posição, nem no volume, nem na constituição física da Terra, que possa induzir à suposição de 


\section{Revista Científica ANAP Brasil}

ISSN 1984-3240 - Volume 14, número 32, 2021

que ela goze do privilégio de ser habitada, com exclusão de tantos milhares de milhões de mundos semelhantes" (Kardec, 2013, p. 71).

As limitações que são próprias das dimensões físicas mostram-se como conclusões equivocadas, quando muitas vezes assumimos as condições de vida na Terra como sendo as únicas para existência de vida. Temos respostas trazidas pelos espíritos que mostram um novo alcance de possibilidades.

\footnotetext{
Pensais então que não há outras fontes de luz e calor além do Sol e em nenhuma conta tendes a eletricidade que, em certos mundos, desempenha um papel que desconheceis e bem mais importante do que o que lhe cabe desempenhar na Terra? Demais, não dissemos que todos os seres são feitos de igual matéria que vós outros e com órgãos de conformação idêntica à dos vossos. (Kardec, 2013, p. 72).
}

Ampliando a visão de mundo a partir das comunicações dos espíritos, temos a multiplicidade de moradas sem qualquer condição de uma compreensão total sem que a ela não se associe uma visão espiritual da vida, visto que "A casa do Pai é o Universo. As diferentes moradas são os mundos que circulam no Espaço infinito e oferecem, aos Espíritos que neles encarnam, moradas correspondentes ao adiantamento dos mesmos Espíritos" (Kardec, 2013, p. 57).

$\mathrm{Na}$ interpretação espiritual dos mundos habitados, há uma associação ao estágio evolutivo dos seres filhos de Deus, aspecto elucidado pelo espírito de $A$ verdade através de Allan $\operatorname{Kardec}(K a r d e c, 2013$ ), quando ele relata a sensação de cada ser que se acha em evolução: mais ou menos depurado e desprendido dos laços materiais que variarão ao infinito, inclusive no meio em que ele se encontra e também sobre o aspecto das coisas, das sensações que experimenta e das percepções que tenha.

\footnotetext{
Enquanto uns não se podem afastar da esfera onde viveram outros se elevam e percorrem o Espaço e os mundos; enquanto alguns Espíritos culpados erram nas trevas, os bem-aventurados gozam de resplendente claridade e do espetáculo sublime do Infinito; finalmente, enquanto o mau, atormentado de remorsos e pesares, muitas vezes insulado, sem consolação, separado dos que constituíam objeto de suas afeições (Kardec, 2013, p. 57).
}

O fato é que a vida na Terra permite o contato com aspectos relacionados à vida material, apesar de não termos consciência de todas as camadas que fazem parte da experiência física com a casa terrena, nossa casa material, podemos ampliar um pouco mais o alcance de associações possíveis entre o significado espiritual da casa terrena para além da casa física que nos serve de abrigo.

Todavia, ainda que estando em um mundo intermediário, a Terra relaciona-se também com mundos inferiores onde a existência é toda material, onde reinam soberanas as paixões, sendo quase nula a vida moral. Assim sendo, à medida que acontece o desenvolvimento, diminui a influência da matéria, de tal maneira que, nos mundos mais adiantados, a vida é, por assim dizer, toda espiritual. (Kardec, 2013).

\section{APROXIMAÇÕES COM A EXPERIÊNCIA DO HABITAR NA TERRA}

O Espiritismo mostra que essa vida não passa de um elo no harmonioso e magnífico conjunto da obra do Criador, de que a solidariedade é quem conjuga todas as existências de um 
mesmo ser, todos os seres de um mesmo mundo e os seres de todos os mundos (Kardec, 2013). A Terra pertence à categoria dos mundos de expiação e provas, razão "porque aí vive o homem a braços com tantas misérias" (Kardec, 2013). Contudo, o período de provas e expiações está findando, o planeta está passando por uma mudança e tornando-se um mundo de regeneração:

\footnotetext{
Os mundos de regeneração, nos quais as almas que ainda têm o que expiar haurem novas forças, repousando das fadigas da luta; mundos ditosos, onde o bem sobrepuja o mal; mundos celestes ou divinos, habitações de Espíritos depurados, onde exclusivamente reina o bem. (Kardec, 2013, p. 58).
}

A experiência na dimensão física, sem perder o contexto dos mundos espirituais relacionados, permite uma experiência espiritual fortalecida por patamares evolutivos no limite das possibilidades em cada ser humano. O espaço físico condiciona a experiência humana em seu percurso espiritual, cuja trajetória da existência inclui a interdependência entre os vários mundos.

Assim sendo, os vários níveis de mundos condicionam uma experiência complexa no mundo físico. É como um recorte que não deixa de lado a totalidade, pelo contrário, particulariza a experiência no percurso evolutivo, mas que é provocada pela dimensão física de habitar o planetaTerra.

Por sua vez, estando totalmente adaptado à dimensão física, a limitação que nos é condicionada para a vida física, via de regra, nos impede, às vezes, de uma compreensão ampla sobre a criação divina e a perfeição do caminho de aprimoramento espiritual, sendo o mundo ao qual se destina apenas um meio para acompanhamento de realização do plano do espírito em sua jornada. A verdade da obra de Deus é expressa por Kardec no livro A Gênese.

\footnotetext{
Que as obras de Deus sejam criadas para o pensamento e a inteligência; que os mundos sejam moradas de seres que as contemplam e lhes descobrem, sob o véu, o poder e a sabedoria daquele que as formou, são questões que já nos não oferecem dúvida; mas, que sejam solidárias as almas que as povoam, é o que importa saber. (Kardec, 1995, p. 135).
}

A dimensão física nos provoca com a noção de espaço que inclui o humano, inclusive em subjetividade, posto que o espaço construído abriga o físico que acolhe o psíquico. Sob essa perspectiva, muito além da materialidade que mais facilmente caracteriza uma morada física, Leitão (2007) destaca a transcendência da casa física ao defender que a construção da casa humana é, na verdade, um espaço para a alma conforme Rykwert (1997) em A casa de Adão no Paraíso.

Para além da primeira morada que o ventre materno propicia, o espaço interior/espaço abrigo permeia a vida humana desde sempre, tornando a experiência de existir em correspondência com a tridimensionalidade da vida na Terra, indissociáveis. A existência é espacial, o que confere às ciências do espaço, como a Arquitetura, um significado existencial (Norberg-Schulz, 1971).

Busca-se um olhar mais ampliado para abordara casa terrena. Não é à toa que a casa física está além de uma aparência, ela tem um significado espiritual. Como assevera Leitão (2007) sobre a casa feita para morar, ela não é o objeto em si mesmo, mas a casa, em seu sentido ampliado e simbólico, é o espaço que acolhe o humano. 
Desse modo, ampliam-se as visões, transcendendo a dimensão física da casa que se expande na experiência com a casa que possibilita, segundo Leitão (2007), real ou ilusoriamente, voltar, entrar, rememorar, permanecer, aprender, amar, proteger-se, dentre outras tantas experiências do habitar.

\section{O ESPAÇO-TEMPO NORTEANDO CONEXÕES ENTRE OS MUNDOS}

Na doutrina espírita, espaço e tempo mostram-se articulados à ideia de imensidão e eternidade dos mundos referentes ao caminho de evolução dos seres espirituais.

\footnotetext{
Espaço é uma dessas palavras que exprimem uma ideia primitiva e axiomática, de si mesma evidente, e a cujo respeito as diversas definições que se possam dar nada mais fazem do que obscurecê-la. Todos sabemos o que é o espaço e eu apenas quero firmar que ele é infinito, a fim de que os nossos estudos ulteriores não encontrem uma barreira opondo-se às investigações do nosso olhar. Ora, digo que o espaço é infinito, pela razão de ser impossível imaginar-se lhe um limite qualquer. e porque, apesar da dificuldade com que topamos para conceber o infinito, mais fácil nos é avançar eternamente pelo espaço, em pensamento, do que parar num ponto qualquer, depois do qual não mais encontrássemos extensão a percorrer. (Kardec, 1995, p. 104).
}

Como a palavra espaço, tempo é também um termo já por si mesmo definido. Dele se faz ideia mais exata, relacionando-o com o todo infinito. O tempo é a sucessão das coisas. Está ligado à eternidade do mesmo modo que as coisas estão ligadas ao infinito (Kardec, 1995).

\footnotetext{
Tantos mundos na vasta amplidão, quantos tempos diversos e incompatíveis. Fora dos mundos, somente a eternidade substitui essas efêmeras sucessões e enche, tranquilamente, da sua luz imóvel a imensidade dos céus. Imensidade sem limites e eternidade sem limites, tais as duas grandes propriedades da natureza universal". (Kardec, 1995, p. 106).
}

$\mathrm{Na}$ tridimensionalidade do mundo físico, a espacialidade é parte integrante da natureza do ser. $\mathrm{O}$ espaço é, portanto, constitutivo da existência humana, pertence à essência do ser. Sendo existencial, ele é funcional, racional e simbólico, incorporando necessidades, expectativas e desejos que fazem parte da existência humana (Malard, 2006).

Ao experimentar espaços, o ser humano passa a experimentar significados, segundo Norberg-Schulz (1963, p. 22), é "quando isto se verifica, o espaço se converte em um conjunto de lugares". O que é confirmado por Tuan (1983), para quem o espaço é dotado de valor, é familiar, insere-se no ambiente físico e é qualificado como lugar.

Rossi (1966) anotou esse ponto essencial do espaço, chamando a atenção para o fato de que o espaço físico qualificado como arquitetônico só pode ser plenamente apreendido pela experiência. É a experiência arquitetônica, como diria Zevi (1977), quando anuncia na segunda metade do séculoXX que a definição mais precisa da Arquitetura é a que leva em conta o espaço interior, onde o ser humano entra, anda e vive.

Pela subjetividade implícita na ideia de viver o espaço é possível compreender o melhor sentido da experiência com o espaço interior ao se sentir por ele envolvida: salvação, reconhecimento, perdão, recompensa etc., todos muito além da função física de abrigo manifesto nas narrativas bíblicas. Portanto, atende às necessidades humanas que vão além da função abrigo. 


\title{
Revista Científica ANAP Brasil
}

\author{
ISSN 1984-3240 - Volume 14, número 32, 2021
}

\begin{abstract}
A luta é sempre necessária ao desenvolvimento do Espírito, pois, mesmo chegando a esse ponto, que parece culminante, ele ainda está longe de ser perfeito. Só à custa de muita atividade adquire conhecimento, experiência e se despoja dos últimos vestígios da animalidade. Mas, nessa ocasião, a luta, de sangrenta e brutal que era, se torna puramente intelectual. $\mathrm{O}$ homem luta contra as dificuldades, não mais contra os seus semelhantes. (Kardec, 1995, p. 83).
\end{abstract}

Assim, a casa terrena também vai além da materialidade e encontra também o espaço para a alma (Leitão, 2006).

\section{CONSIDERAÇÕES FINAIS}

A experiência humana na dimensão física é iniciada pela noção de segurança do estar dentro de um espaço tridimensional, sendo a primeira experiência dessa natureza o ventre materno. A casa terrena é um sucedâneo do útero, a primeira morada cuja memória talvez persista em nós, onde estávamos seguros e sentíamos bem-estar (Freud, 1929-30, p. 30-34).

Ainda que na tridimensionalidade do espaço-tempo, são várias as nuances estabelecidas entre cada ser humano e seu entorno físico, a relação entre sujeito e objeto é fonte de conhecimento para os conteúdos que estão além da dimensão física, pois guardam memórias de vários mundos habitados nas múltiplas existências.

As idas e vindas entre os aspectos envolvidos nas várias moradas que estão impressos na alma, guardam significados que se manifestam na casa física, tornando a experiência humana única. Na dimensão física, a experiência torna-se mais limitada à tridimensionalidade, mas, via de regra, escapam conteúdos que estão além da experiência puramente física.

As aproximações possíveis entre o conhecimento espiritual de fonte kardecista demonstrou alguns pilares a serem explorados para conter as interpretações físicas da ampla caminhada espiritual que todos os seres gravitam até chegar a mundos mais evoluídos do que a Terra.

A compreensão que vai se mostrando frutífera sobre o significado da casa terrena à luz do Espiritismo torna possível um maior cruzamento de percepções entre mundo espiritual e mundo físico. Passo a passo, é permitido discutir a produção do espaço físico abrangendo um conhecimento técnico que mescla necessidades imediatas de espaço físico com necessidades existenciais que apresentam uma natureza espiritual. Tudo isso para nos elevarmos espiritualmente.

\footnotetext{
Há também considerações morais de ordem elevada. É necessária a luta para o desenvolvimento do Espírito. Na luta é que ele exercita suas faculdades. O que ataca em busca do alimento e o que se defende para conservar a vida usam de habilidade e inteligência, aumentando, em consequência, suas forças intelectuais. Um dos dois sucumbe; mas, em realidade, que foi o que o mais forte ou o mais destro tirou ao mais fraco? A veste de carne, nada mais; ulteriormente, o Espírito, que não morreu, tomará outra. (Kardec, 1995, p. 82).
}

No plano físico, temos no campo da Arquitetura muitos instrumentos para análise e concepção do espaço construído como cenário da vida e das atividades humanas, e que mesmo sendo um campo mais reconhecido por sua instância formal, a discussão que aqui se apresenta vai ao encontro da interação entre ser humano e o espaço físico, chegando à experiência humana na vida espacial pela dimensão física. 


\section{Revista Científica ANAP Brasil}

ISSN 1984-3240 - Volume 14, número 32, 2021

Desse modo, na imensidão dos mundos e no tempo infinito mostram-se várias moradas, sendo o planeta Terra aquele relacionado ao corpo físico e que encontra refúgio na casa terrena como parte de um caminho de aprendizados conforme o grau de aprimoramento espiritual até os mundos elevados na pátria espiritual.

São muitas vidas, muitas moradas, e na casa terrena temos a grande oportunidade de amadurecimento, entre as idas e vindas do ser divino que somos pelo caminho da evolução espiritual.

\section{REFERÊNCIAS}

KARDEC, Allan. O livro dos espíritos. Brasília: FED, 2013.

KARDEC, Allan. A Gênese. Brasília: FED, 1995.

FREUD, Sigmund. Obras completas. Madri: Editorial Biblioteca Nueva (1973 [1929-30]). p. 30-34.

MALARD, Maria Lucia. As aparências em Arquitetura. Belo Horizonte: Ed. UFMG, 2006.

LEITÃO, Lucia. Entra na tua casa: anotações sobre arquitetura, espaço e subjetividade. In. LEITÃO. Lucia; AMORIM. Luiz (org.). A casa nossa de cada dia. Recife: Ed. Universitária da UFPE, 2007. pp. 49-69.

NORBERG-SCHULZ, Christian. Intentions in architecture. Cambridge: MIT Press, 1963.

NORBERG-SCHULZ, Christian. Existence, space and architecture. New York: Praerger, 1971.

RYKWERT, Joseph. On Adam's house in Paradise. Cambridge: MIT Press, 1977.

ROSSI, Aldo. Arquitetura da Cidade. São Paulo: Martins Fontes, 1995.

TUAN, Yi-Fu. Espaço e lugar: a perspectiva da experiência. São Paulo: Difel, 1983.

ZEVI, B. Saber ver a Arquitetura. Lisboa: Editorial Minerva, 1977. 